\title{
Tratamentos pré-germinativos em sementes de quiabo em diferentes estádios de maturação do fruto
}

\section{Pre-germinative treatments in okra seeds in different stadiums of fruit maturation}

\author{
Camila Aparecida da Silva Martins ${ }^{1 *}$; José Carlos Lopes²; Célia Maria Peixoto de \\ Macêdo $^{3}$
}

\section{Resumo}

O objetivo deste trabalho foi avaliar a influência da pré-embebição e da termoterapia na germinação e no vigor das sementes de quiabo (Abelmoschus esculentus) em diferentes estádios de maturação do fruto. $\mathrm{O}$ delineamento foi o inteiramente casualizado com quatro repetições, num esquema fatorial $5 \times 9$, cinco estádios de maturação (verde, semi-duro, duro, seco e deiscente) e nove tratamentos pré-germinativos: pré-embebição por imersão das sementes em água à temperatura de $30^{\circ} \mathrm{C}$ por 6,12 e 24 horas; imersão das sementes em água a $40,50,60$ e $70^{\circ} \mathrm{C}$ por 3 minutos; termoterapia por imersão das sementes em água à temperatura de ebulição $\left(97^{\circ} \mathrm{C}\right)$ até esfriar e sementes intactas (testemunha). As sementes foram semeadas em rolos de papel-toalha que foram mantidos em câmara tipo BOD regulada a $20-30^{\circ} \mathrm{C}$ e fotoperíodo de 8-16 horas. As sementes de quiabo oriundas de frutos secos e deiscentes apresentam maior desempenho germinativo. Os tratamentos pré-germinativos mais eficientes para acelerar a germinação das sementes obtidas de frutos secos e deiscentes são a pré-embebição por 6 horas e a termoterapia a $60^{\circ} \mathrm{C}$ por 3 minutos, respectivamente.

Palavras-chave: Abelmoschus esculentus, germinação, vigor, dormência tegumentar

\begin{abstract}
The objective of this work was to evaluate the influence of the pre-soak and of the thermotherapy in the germination and in the energy of the okra seeds (Abelmoschus esculentus) in different stadiums of maturation of the fruit. The design used was the entirely randomized with four repetitions, in a factorial outline $5 \times 9$, five maturation stadiums (green, semi-hard, hard, dry and dehiscent) and nine treatments pre-germination: pre-soak for immersion of the seeds in water to the temperature of $30^{\circ} \mathrm{C}$ for 6,12 and 24 hours; immersion of the seeds in water to $40,50,60$ and $70^{\circ} \mathrm{C}$ for 3 minutes; thermotherapy for immersion of the seeds in water to the ebullition temperature $\left(97^{\circ} \mathrm{C}\right)$ until cooling and intact seeds (control). The seeds were sowed in paper-towel rolls and they were maintained in camera type BOD regulated to $20-30^{\circ} \mathrm{C}$ and photoperiod of $8-16$ hours. The okra seeds originating from dry and dehiscent fruits presented larger germination performance. The pre-germination treatments more effective to accelerate the germination of seeds obtained from dry and dehiscent fruits are the pre-soak for 6 hours and thermotherapy at $60^{\circ} \mathrm{C}$ for 3 minutes, respectively.
\end{abstract}

Key words: Abelmoschus esculentus, germination, vigor, tegument dormancy

1 Doutoranda em Produção Vegetal. Bolsista CAPES/REUNI do Programa de Pós-Graduação em Produção Vegetal do Centro de Ciências Agrárias da Universidade Federal do Espírito Santo, CCA/UFES, Cx. Postal 16, CEP: 29.500-000. Alegre, ES. E-mail: camila.cca@hotmail.com

2 Prof. Associado II Dr. da Universidade Federal do Espírito Santo, UFES, Dept ${ }^{\circ}$ de Produção Vegetal, Cx. Postal 16, CEP: 29.500000. Alegre, ES. E-mail: jcufes@bol.com.br

3 Doutoranda em Produção Vegetal da Universidade Estadual do Norte Fluminense 'Darcy Ribeiro', UENF, CEP:28013-602, Campos dos Goytacazes, RJ. E-mail: celiampm@yahoo.com.br

* Autor para correspondência

Recebido para publicação 06/07/2010 Aprovado em 08/07/2011 


\section{Introdução}

A espécie Abelmoschus esculentus, conhecida vulgarmente como quiabo, pertencente à família Malvaceae, é uma planta anual, arbustiva, de porte ereto e caule semilenhoso que pode atingir $3 \mathrm{~m}$ de altura. As flores são grandes e amareladas. Os frutos, pilosos, são do tipo cápsula, roliços, apresentando seção transversal circular ou pentagonal. A produção de frutos ocorre tanto na haste principal como nas laterais, iniciando-se com a planta ainda pequena. São poucas as cultivares disponíveis para cultivo, todas de origem nacional. A mais destacada e disseminada é a Santa Cruz 47, que se caracteriza por apresentar plantas vigorosas e de internódios curtos; com porte baixo que facilita a colheita, sendo a semente o principal veículo de propagação (FILGUEIRA, 2008).

A maturidade fisiológica das sementes é geralmente acompanhada por visíveis mudanças no aspecto externo e na coloração dos frutos e das sementes. Pela forma de comercialização e por apresentarem alto valor comercial, as sementes de olerícolas merecem uma atenção especial no que se refere à avaliação de sua qualidade fisiológica (NAKAGAWA; CAVARIANI; ZUCARELI, 2005). Para isso, testes para determinação da germinação e do índice de velocidade de germinação (IVG) das sementes devem ser utilizados com maior freqüência (SOUZA et al., 2007).

As sementes com tegumento impermeável a água são conhecidas como sementes duras (MARCOS FILHO, 2005). Trabalhando com sementes de quiabo, Eichelberger e Moraes (2001) relatam que estas sementes apresentam esta característica, o que pode acarretar emergência lenta e irregular, gerando desuniformidade de plântulas no campo, o que contribui para elevar o gasto de sementes.

Segundo Castro e Hilhorst (2004), a água exerce forte influência sobre o processo germinativo, sendo observado que, em sementes nas quais se utiliza o tratamento pré-germiantivo por meio de pré-embebição em solução, a germinação acontece de forma rápida e uniforme. De fato, o efeito benéfico da pré-embebição sobre a velocidade de germinação está relacionado diretamente com a absorção de água durante a primeira etapa do processo germinativo, sendo possível que as sementes já tenham completado, parcial ou totalmente, essa fase por ocasião da semeadura (BEWLEY; BLACK, 1994). Neste sentido, a água tem papel fundamental na compreensão da biologia da semente, particularmente nos processos de germinação e desenvolvimento inicial das plântulas.

De acordo com Bertagnolli et al. (2003), a velocidade de absorção de água e as reações bioquímicas que ocorrem no interior da semente são influenciadas pela barreira imposta pelo tegumento das sementes e pela temperatura, sendo os limites desta última variáveis para cada espécie vegetal. As sementes de quiabo apresentam dificuldades na germinação devido à presença de substâncias gordurosas na constituição de seu tegumento, que dificultam a absorção de água (SONNENBERG, 1985). Isto explica o fato de que mesmo submetidas às condições ótimas de umidade, luz, temperatura e oxigênio, essa espécie apresenta desuniformidade na germinação como conseqüência do estado de dormência das sementes (MAYER; POLJAKOFF-MYBER, 1989). Apesar do fenômeno de dormência permitir que a natureza distribua a germinação no tempo (FOWLER; MARTINS, 2001), para favorecer e garantir a sobrevivência das espécies (CARVALHO; NAKAGAWA, 2000), há a necessidade de facilitar a entrada de água no interior da semente para que a germinação ocorra. Isto pode ser realizado por meio da aplicação de tratamentos pré-germinativos que visam a superação da dureza tegumentar das sementes de espécies que apresentam tal característica (SOUZA; MARTINS; SADER, 1992). Em 
laboratórios, diversos métodos têm sido empregados, visando à superação da dormência por impedimento à entrada de água, tais como: a escarificação mecânica e química, a embebição das sementes em água e tratamentos com altas temperaturas, sob condição úmida ou seca. Contudo, a aplicação e eficiência desses métodos dependem da causa e do grau da dormência, o que é bastante variável entre as espécies (LIMA; GARCIA, 1996).

A imersão em água quente é um dos métodos que possibilita modificar a permeabilidade do tegumento das sementes, que junto com a ação do calor pode estimular o processo germinativo (VAZQUEZ-YANES, 1975). Filgueira (1987) recomenda para a superação de dormência em sementes de quiabo a imersão em álcool, em acetona e em água durante 24 horas. A embebição em água sob temperatura ambiente algumas vezes aumenta a velocidade de germinação da semente. A água quente ou fervente também é bastante utilizada e tem se mostrado eficiente na superação de dormência de sementes de várias espécies florestais (BRASIL, 2009). Além disso, outra técnica utilizada para potencializar a entrada de água nas sementes é a termoterapia, definida por diversos autores como um método que consiste na exposição das sementes à ação do calor em combinação com o tempo de tratamento para romper a dureza do tegumento.

A termoterapia pode ser aplicada via calor úmido (água quente ou vapor) ou calor seco. Este último apresenta menor capacidade térmica ou troca de calor que a via úmida, requerendo, portanto, maior tempo de exposição. Entretanto, é mais simples e mais acessível, além de causar menos danos às sementes, já que não há o rompimento do tegumento e extravasamento de substâncias das sementes, comum na embebição em água quente e vapor arejado para remover substâncias cerosas das sementes e aumentar a velocidade de entrada da água pelo calor devido a agitação maior das moléculas (MENTEN,
1995). Entre os métodos de tratamento de sementes descritos na literatura, esse é um dos mais citados para erradicação de fitobactérias localizadas interna ou externamente nas sementes (ZAMBOLIM; VALE; COSTA, 1997).

A termoterapia a temperatura de $60^{\circ} \mathrm{C}$ e $70^{\circ} \mathrm{C}$ é recomendada para a superação de dormência em sementes de $A$. esculentus (FERNANDES; CUNHA, 1990; LOPES et al., 2006a), além de ser eficiente na erradicação de Xanthomonas campestris pv. vesicatoria em sementes de Lycopersicon esculentum (SILVA et al., 2002). Para Coutinho et al. (2007), a termoterapia apesar de ser eficiente no controle de patógenos associados às sementes, pode causar danos à sua qualidade fisiológica, principalmente pelo rompimento das membranas celulares ou desnaturação de proteínas dos tecidos externos, os quais podem ocasionar a perda de metabólitos que podem ser utilizados na germinação e no crescimento da plântula.

Diante do exposto, este trabalho objetivouse em avaliar a influência da pré-embebição e da termoterapia e dos diferentes estádios de maturação dos frutos na germinação e no vigor de sementes de quiabo.

\section{Material e Métodos}

O trabalho foi conduzido no Laboratório de Tecnologia e Análise de Sementes do Departamento de Produção Vegetal do Centro de Ciências Agrárias da Universidade Federal do Espírito Santo (CCA-UFES) em Alegre - ES. Foram utilizadas sementes de quiabo cultivar Santa Cruz 47 provenientes de plantas matrizes, em Março de 2007, cultivadas no campus do CCA-UFES de São José do Calçado - ES.

As flores foram etiquetadas na antese e as sementes foram extraídas, manualmente, após a colheita dos frutos realizada aos 15, 17, 20, 23 e 27 dias após a antese (DAA), sendo os frutos 
classificados como verdes (15 a 16 DAA), semiduro (17 a 19 DAA), duro (20 a 22 DAA), seco (23 a 26 DAA) e deiscente (aos 27 DAA).

Os tratamentos pré-germiantivos utilizados foram a pré-embebição por imersão das sementes em água à temperatura de $30^{\circ} \mathrm{C}$ por 6, 12 e 24 horas (h); termoterapia por imersão das sementes em água a $40,50,60$ e $70^{\circ} \mathrm{C}$ por 3 minutos; termoterapia por imersão das sementes em água à temperatura de ebulição $\left(97^{\circ} \mathrm{C}\right)$ até esfriar. Sementes nas quais não se fez uso de nenhum tipo de tratamento para superação da dureza foram utilizadas como controle. Após serem submetidas aos tratamentos, as sementes tratadas e as do controle foram colocadas sobre duas folhas de papel Germitest ${ }^{\circledR}$ e cobertas com outra folha para a confecção dos rolos nos quais foram distribuídas 25 sementes e caracterizando uma repetição, sendo utilizadas quatro repetições por tratamento. O papel foi umedecido com água destilada, na proporção de 2,5 vezes o peso do papel e os rolos mantidos em câmara do tipo BOD regulada a $20-30^{\circ} \mathrm{C}$ e fotoperíodo de 8-16 horas luz/escuro (BRASIL, 2009).

Para testar o efeito dos tratamentos, avaliouse a Germinação: considerando-se o número de plântulas normais aos 4 (primeira contagem de germinação) e aos 21dias após a instalação do teste, de acordo com o recomendado pelas Regras para Análise de Sementes (BRASIL, 2009); Índice de Velocidade de Germinação (IVG): conduzido juntamente com o teste de germinação, realizou-se contagem diária das sementes nas quais se observou a protrusão da raiz primária com $2 \mathrm{~mm}$ de comprimento sendo o cálculo do IVG efetuado segundo a fórmula proposta por Maguire (1962).

O delineamento estatístico utilizado foi o inteiramente casualizado em arranjo fatorial 5 X 9 (Estádios de maturação X Tratamentos pré-germinativos). Os dados observados foram submetidos à análise de variância pelo teste F a $5 \%$ de significância e as médias foram comparadas pelo teste de Tukey a 5\% de probabilidade, utilizando-se o programa SAEG 9.1 (UFV, 2007).

\section{Resultados e Discussão}

As sementes oriundas de frutos verdes (15 - 16 DAA) não germinaram, observando-se ao final do teste de germinação a deterioração das mesmas. As sementes obtidas de frutos semi-duro (17 - 19 DAA) e duro (20 - 22 DAA) apresentaram baixa germinação, cujas porcentagens variaram de 0 a $2 \%$ (Tabela 1). Estes resultados evidenciam que as sementes colhidas de frutos verdes, semiduros e duros não apresentam bom desempenho germinativo por estarem imaturas, sendo irrelevante, neste caso, fazer alguma inferência aos tratamentos pré-germinativos aplicados a essas sementes. Contudo, as sementes de quiabo nos estádios de maturação do fruto seco (23 26 DAA) e deiscente (27 DAA) apresentaram melhor desempenho germinativo quando submetidas aos tratamentos pré-germinativos em estudo. Com exceção ao tratamento termoterapia a $97^{\circ} \mathrm{C}$ até esfriar, que reduz drasticamente o percentual de germinação e o índice de velocidade de germinação (IVG) das sementes em estudo (Tabelas 1 e 2), por promover a morte do embrião. No entanto, verifica-se que houve diferença significativa entre a germinação das sementes oriundas de frutos secos e deiscentes que não foram submetidas aos tratamentos pré-germinativos (testemunha) e que foram submetidas aos tratamentos de termoterapia a $40^{\circ} \mathrm{C}$ e termoterapia a $50^{\circ} \mathrm{C}$ por 3 minutos (Tabela 1), onde as sementes oriundas de frutos deiscentes apresentaram melhor desempenho germinativo. 
Tabela 1. Germinação (\%) de sementes de quiabo, cultivar Santa Cruz 47, oriundas de diferentes estádios dematuração dos frutos, submetidas a tratamentos pré-germinativos. CCA-UFES, Alegre-ES, 2007.

\begin{tabular}{llcccc}
\hline Tratamentos & \multicolumn{5}{c}{ Maturação do fruto $^{2}$} \\
\cline { 2 - 6 } pré-germinativos & Verde & Semi-duro & Duro & Seco & Deiscente \\
\hline Testemunha & $0 \mathrm{C} \mathrm{a}$ & $1 \mathrm{C} \mathrm{a}$ & $2 \mathrm{C} \mathrm{a}$ & $63 \mathrm{~B} \mathrm{ab}$ & $82 \mathrm{~A} \mathrm{a}$ \\
Pré-embebição $/ 6 \mathrm{~h}$ & $0 \mathrm{~B} \mathrm{a}$ & $0 \mathrm{~B} \mathrm{a}$ & $0 \mathrm{~B} \mathrm{a}$ & $75 \mathrm{~A} \mathrm{a}$ & $68 \mathrm{~A} \mathrm{abc}$ \\
Pré-embebição $/ 12 \mathrm{~h}$ & $0 \mathrm{~B} \mathrm{a}$ & $1 \mathrm{~B} \mathrm{a}$ & $0 \mathrm{~B} \mathrm{a}$ & $70 \mathrm{~A} \mathrm{ab}$ & $78 \mathrm{~A} \mathrm{abc}$ \\
Pré-embebição $/ 24 \mathrm{~h}$ & $1 \mathrm{~B} \mathrm{a}$ & $1 \mathrm{~B} \mathrm{a}$ & $1 \mathrm{~B} \mathrm{a}$ & $66 \mathrm{~A} \mathrm{ab}$ & $77 \mathrm{~A} \mathrm{abc}$ \\
Termoterapia $40^{\circ} \mathrm{C} / 3$ minutos & $0 \mathrm{C} \mathrm{a}$ & $0 \mathrm{C} \mathrm{a}$ & $1 \mathrm{C} \mathrm{a}$ & $58 \mathrm{~B} \mathrm{~b}$ & $78 \mathrm{~A} \mathrm{abc}$ \\
Termoterapia $50^{\circ} \mathrm{C} / 3$ minutos & $0 \mathrm{C} \mathrm{a}$ & $0 \mathrm{C} \mathrm{a}$ & $0 \mathrm{C} \mathrm{a}$ & $57 \mathrm{~B} \mathrm{~b}$ & $72 \mathrm{~A} \mathrm{abc}$ \\
Termoterapia $60^{\circ} \mathrm{C} / 3$ minutos & $0 \mathrm{~B} \mathrm{a}$ & $0 \mathrm{~B} \mathrm{a}$ & $2 \mathrm{~B} \mathrm{a}$ & $69 \mathrm{~A} \mathrm{ab}$ & $81 \mathrm{~A} \mathrm{abc}$ \\
Termoterapia $70^{\circ} \mathrm{C} / 3$ minutos & $0 \mathrm{~B} \mathrm{a}$ & $0 \mathrm{~B} \mathrm{a}$ & $0 \mathrm{~B} \mathrm{a}$ & $68 \mathrm{~A} \mathrm{ab}$ & $67 \mathrm{~A} \mathrm{abc}$ \\
Termoterapia $97^{\circ} \mathrm{C}$ até esfriar & $1 \mathrm{~A} \mathrm{a}$ & $1 \mathrm{~A} \mathrm{a}$ & $1 \mathrm{~A} \mathrm{a}$ & $0 \mathrm{~A} \mathrm{c}$ & $9 \mathrm{~A} \mathrm{~cd}$ \\
\hline
\end{tabular}

${ }^{1}$ Médias seguidas de mesma letra maiúscula na linha e minúscula na coluna não diferem entre si pelo teste de Tukey a $5 \%$ de probabilidade.

${ }^{2}$ Verde (15-16 DAA), semi-duro (17-19 DAA), duro (20-22 DAA), seco (23-26 DAA) e deiscente (27 DAA), sendo DAA $=$ Dias após a antese

Os resultados de germinação das sementes de quiabo obtidas de frutos secos variaram de zero a $75 \%$. Além disso, verifica-se que o tratamento de pré-embebição por 6 horas que forneceu maior valor de germinação para as sementes oriundas de frutos seco não diferiu significativamente da testemunha, dos demais tratamentos de pré-embebição e das termoterapias a $60^{\circ} \mathrm{C}$ e $70^{\circ} \mathrm{C}$ por 3 minutos aplicados a essas sementes, considerados, portanto, também eficientes para aumentar a germinação destas sementes em relação à testemunha. Os resultados de germinação das sementes de frutos deiscentes variaram de 9 a $82 \%$, e o maior desempenho germinativo foi observado nas sementes sem tratamentos (controle), embora os tratamentos de pré-embebição por 12 e 24 horas e as termoterapias a 40,50 e $60^{\circ} \mathrm{C}$ por 3 minutos não tenham diferido estatisticamente do controle. Resultados semelhantes foram obtidos por Lopes et al. (2006a), em sementes de quiabo em início de deiscência submetidas as termoterapias a 40,50 e $60^{\circ} \mathrm{C}$ por 3 minutos para superar a dormência física das sementes.

As sementes de quiabo obtidas de frutos seco e deiscente que não foram submetidas aos tratamentos pré-germinativos (testemunha) apresentaram germinação de $63 \%$ e $82 \%$, respectivamente (Tabela 1). Estes valores estão abaixo e acima do padrão de germinação estabelecido para as sementes desta cultura no Brasil que é de 70\% (CASTRO, 2005). Com a aplicação dos tratamentos pré-germinativos de pré-embebição por 6 e 12 horas, observa-se, para as sementes de fruto seco, aumento de 7 e 12 pontos percentuais na germinação destas sementes em relação à testemunha. Para as sementes de fruto deiscente, verifica-se que os tratamentos de préembebição por 12 e 24 horas e de termoterapia a 40, 50 e $60^{\circ} \mathrm{C}$ por 3 minutos contribuíram para manter a germinação destas sementes acima do padrão de germinação estabelecido para as sementes de quiabo. Estes resultados indicam que o uso de tratamentos pré-germinativos contribuem para aumentar a porcentagem de germinação e manter a qualidade fisiológica das sementes de quiabo oriundas de fruto seco e deiscente.

Os resultados obtidos por Zanin, Nakagawa e Setubal (1998), com a cultivar Amarelinho mostraram que os maiores valores para a porcentagem de germinação (acima de 92\%), foram 
obtidos de sementes oriundas de frutos colhidos aos 55 dias após a antese. Entretanto, no presente trabalho com a cultivar Santa cruz 47, verificouse $82 \%$ de germinação (Tabela 1 ) em sementes de frutos deiscentes (27 DAA), evidenciando uma precocidade da maturação das sementes da cultivar em estudo.

Verifica-se que houve resposta diferenciada das sementes em estudo quanto ao tratamento mais eficiente para aumentar a germinação em relação à testemunha (Tabela 1). Para as sementes de frutos seco, o maior valor de germinação foi obtido com o tratamento de pré-embebição por imersão em água por 6 horas, enquanto que para as sementes de fruto deiscente a termoterapia por imersão em água a $60^{\circ} \mathrm{C}$ por 3 minutos foi o tratamento que proporcionou maior germinação. Contudo, observa-se que, para as sementes oriundas de frutos seco e deiscente, os tratamentos que forneceram maiores valores de germinação não diferiram significativamente de outros, considerados, portanto, também eficientes para aumentar a germinação em relação à testemunha. Por exemplo, para as sementes de fruto seco, a germinação das sementes da testemunha que era $63 \%$ foi elevada para $75 \%$ após o tratamento de pré-embebição por imersão em água por 6 horas, embora este tratamento também não tenha diferido significativamente da testemunha, dos tratamentos de pré-embebição com imersão em água por 12 e 24 horas e de termoterapia a 60 e $70^{\circ} \mathrm{C}$ por 3 minutos, o que difere dos resultados obtidos por Dias et al. (1999), com sementes recém-colhidas da cultivar Amarelinho AG338.

Portanto, é importante ressaltar que, de modo geral, considerando as sementes obtidas de frutos seco e deiscente, os tratamentos de pré-embebição por imersão em água por 6 horas e termoterapia a $60^{\circ} \mathrm{C}$ por 3 minutos, respectivamente, contribuíram para aumentar a germinação das sementes de quiabo em relação à testemunha e aos demais tratamentos pré-germinativos aplicados às sementes. Pode-se inferir que dentre estes tratamentos, a termoterapia por imersão das sementes em água a diferentes temperaturas em um mesmo intervalo de tempo se destaca como um dos métodos de superação da dureza tegumentar mais prático e rápido, especialmente, quando comparado com a pré-embebição por imersão das sementes em água à temperatura de $30^{\circ} \mathrm{C}$ por 6, 12 e 24 horas, que aumenta o tempo necessário para a aplicação do tratamento. A eficiência da préembebição em água e da termoterapia tem sido atestada por diversos autores, como constatado em sementes de A. esculentus (COELHO et al., 1983; FILGUEIRA, 1987; FERNANDES; CUNHA, 1990; SOUZA; MARTINS; SADER, 1992; LOPES et al., 2006a; LOPES, 2007), Lycopersicon esculentum (SILVA et al., 2002), Bauhinia divaricata L. (ALVES et al., 2004), e Schyzolobium parahyba (Vell.) Blake (MATHEUS; LOPES, 2007), onde houve aumento expressivo na germinação das sementes submetidas a esses tratamentos pré-germinativos.

Pelos resultados de primeira contagem de germinação (Tabela 2), que representa a velocidade de germinação das sementes, verifica-se, para as sementes oriundas de frutos seco, que os tratamentos de pré-embebição em água à temperatura de $30^{\circ} \mathrm{C}$ por 6, 12 e 24 horas e de termoterapia com a imersão das sementes em água a 60 e $70^{\circ} \mathrm{C}$ por 3 minutos aplicados às sementes contribuíram para acelerar a germinação. Nas sementes de frutos secos, cuja germinação da testemunha na data da primeira contagem foi de $57 \%$, obtiveram-se aumentos que variaram de 5 a 10 pontos percentuais, sendo este último verificado no tratamento pré-embebição em água por 6 horas. Nas sementes obtidas de frutos deiscentes, cuja testemunha apresentou $67 \%$ de germinação na primeira contagem, obtiveram-se aumentos que variaram de 1 a 4 pontos percentuais, sendo este último verificado no tratamento préembebição em água por 12 horas. Em geral, para as sementes de frutos deiscentes, os tratamentos mais eficientes para acelerar a germinação foram a pré-embebição em água por 12 e 24 horas e a termoterapia a $60^{\circ} \mathrm{C}$ por 3 minutos em relação à testemunha, como pode ser visto na (Tabela 2). 
Tabela 2. Primeira contagem de germinação (\%) de sementes de quiabo, cultivar Santa Cruz 47, oriundas de diferentes estádios de maturação dos frutos, submetidas a tratamentos pré-germinativos. CCA-UFES, Alegre-ES, 2007.

\begin{tabular}{lccccc}
\hline Tratamentos & \multicolumn{5}{c}{ Maturação do fruto $^{2}$} \\
\cline { 2 - 5 } pré-germinativos & Verde & Semi-duro & Duro & Seco & Deiscente \\
\hline Testemunha & $0 \mathrm{~B} \mathrm{a}$ & $1 \mathrm{~B} \mathrm{a}$ & $2 \mathrm{~B} \mathrm{a}$ & $57 \mathrm{~A} \mathrm{ab}$ & $67 \mathrm{~A} \mathrm{ab}$ \\
Pré-embebição / $6 \mathrm{~h}$ & $0 \mathrm{~B} \mathrm{a}$ & $0 \mathrm{~B} \mathrm{a}$ & $0 \mathrm{~B} \mathrm{a}$ & $67 \mathrm{~A} \mathrm{a}$ & $60 \mathrm{~A} \mathrm{ab}$ \\
Pré-embebição $/ 12 \mathrm{~h}$ & $0 \mathrm{~B} \mathrm{a}$ & $0 \mathrm{~B} \mathrm{a}$ & $0 \mathrm{~B} \mathrm{a}$ & $66 \mathrm{~A} \mathrm{a}$ & $71 \mathrm{~A} \mathrm{a}$ \\
Pré-embebição $/ 24 \mathrm{~h}$ & $0 \mathrm{~B} \mathrm{a}$ & $0 \mathrm{~B} \mathrm{a}$ & $0 \mathrm{~B} \mathrm{a}$ & $65 \mathrm{~A} \mathrm{a}$ & $69 \mathrm{~A} \mathrm{ab}$ \\
Termoterapia $40^{\circ} \mathrm{C} / 3$ minutos & $0 \mathrm{~B} \mathrm{a}$ & $0 \mathrm{~B} \mathrm{a}$ & $0 \mathrm{~B} \mathrm{a}$ & $55 \mathrm{~B} \mathrm{ab}$ & $63 \mathrm{~A} \mathrm{ab}$ \\
Termoterapia $50^{\circ} \mathrm{C} / 3$ minutos & $0 \mathrm{~B} \mathrm{a}$ & $0 \mathrm{~B} \mathrm{a}$ & $0 \mathrm{~B} \mathrm{a}$ & $49 \mathrm{~A} \mathrm{ab}$ & $60 \mathrm{~A} \mathrm{ab}$ \\
Termoterapia $60^{\circ} \mathrm{C} / 3$ minutos & $0 \mathrm{~B} \mathrm{a}$ & $0 \mathrm{~B} \mathrm{a}$ & $0 \mathrm{~B} \mathrm{a}$ & $62 \mathrm{~A} \mathrm{ab}$ & $68 \mathrm{~A} \mathrm{abc}$ \\
Termoterapia $70^{\circ} \mathrm{C} / 3$ minutos & $0 \mathrm{~B} \mathrm{a}$ & $0 \mathrm{~B} \mathrm{a}$ & $0 \mathrm{~B} \mathrm{a}$ & $65 \mathrm{~A} \mathrm{ab}$ & $57 \mathrm{~A} \mathrm{ab}$ \\
Termoterapia $97^{\circ} \mathrm{C}$ até esfriar & $1 \mathrm{~A} \mathrm{a}$ & $0 \mathrm{~A} \mathrm{a}$ & $0 \mathrm{~A} \mathrm{a}$ & $0 \mathrm{~A} \mathrm{c}$ & $6 \mathrm{~A} \mathrm{ab}$ \\
\hline
\end{tabular}

${ }^{1}$ Médias seguidas de mesma letra maiúscula na linha e minúscula na coluna não diferem entre si pelo teste de Tukey a $5 \%$ de probabilidade.

${ }^{2}$ Verde (15-16 DAA), semi-duro (17-19 DAA), duro (20-22 DAA), seco (23-26 DAA) e deiscente (27 DAA), sendo $\mathrm{DAA}=$ Dias após a antese.

O vigor das sementes em estudo foi avaliado por meio da primeira contagem de germinação e do IVG, que inferem sobre a velocidade de germinação. Segundo Krzyzanowski, Vieira e França Netto (1999), quanto mais rápido for o processo de germinação das sementes, maior será a sua capacidade de emergir mais rápido, ficando menos tempo exposta às condições adversas do solo. Deste modo, as medidas que avaliam a velocidade de germinação podem ser utilizadas de forma eficiente para avaliar o vigor de lotes de sementes.

No presente trabalho, em sementes de quiabo, nos estádios de maturação de frutos secos e deiscentes os valores de IVG variaram de 10,25 a 16,36 e 11,25 a 15,40 , respectivamente, com exceção do tratamento de termoterapia a $97^{\circ} \mathrm{C}$ até esfriar (Tabela 3 ). Nos tratamentos de préembebição por 6 horas e termoterapia a $70^{\circ} \mathrm{C}$ por 3 minutos ocorreu diferença significativa no vigor das sementes entre os estádios de maturação de frutos, nos quais as sementes obtidas de frutos secos apresentaram maior velocidade de germinação. O baixo vigor das sementes oriundas de frutos deiscentes pode estar relacionado à temperatura elevada do tratamento de termoterapia citado, sob o qual as sementes de frutos secos apresentaram resistência. Entretanto, nos demais tratamentos o fator estádio de maturação do fruto não apresentou efeito sobre o IVG.

Os valores médios do IVG apresentaram diferenças significativas, entre os tratamentos termoterapia a $97^{\circ} \mathrm{C}$ até esfriar, para os demais tratamentos pré-germinativos aplicados às sementes de quiabo oriundas de frutos seco e deiscente (Tabela 3). Os tratamentos testemunha, pré-embebição por 6,12 e 24 horas e termoterapia a $40,50,60$ e $70^{\circ} \mathrm{C}$ por 3 minutos não diferiram, entre si, para todos os estádios de maturação dos frutos testados. Além disso, o IVG apontou as sementes de frutos seco e deiscente como as sementes de quiabo mais promissoras para a germinação, o que corrobora os resultados obtidos por Lopes et al. (2006b), onde as sementes de quiabo obtidas de frutos seco e deiscente apresentaram maior germinação e IVG. 
Tabela 3. Índice de velocidade de germinação (IVG) de sementes de quiabo, cultivar Santa Cruz 47, oriundas de diferentes estádios de maturação dos frutos, submetidas a tratamentos pré-germinativos. CCAUFES, Alegre-ES, 2007.

\begin{tabular}{lccccc}
\hline Tratamentos & \multicolumn{5}{c}{ Maturação do fruto $^{2}$} \\
\cline { 2 - 6 } pré-germinativos & Verde & Semi-duro & Duro & Seco & Deiscente \\
\hline Testemunha & $0,00 \mathrm{~B} \mathrm{a}$ & $10,13 \mathrm{~B} \mathrm{a}$ & $0,25 \mathrm{~B} \mathrm{a}$ & $12,13 \mathrm{~A} \mathrm{bc}$ & $12,62 \mathrm{~A} \mathrm{abc}$ \\
Pré-embebição / $6 \mathrm{~h}$ & $0,00 \mathrm{C} \mathrm{a}$ & $0,00 \mathrm{C} \mathrm{a}$ & $0,00 \mathrm{C} \mathrm{a}$ & $15,72 \mathrm{~A} \mathrm{a}$ & $12,07 \mathrm{~B} \mathrm{abc}$ \\
Pré-embebição $/ 12 \mathrm{~h}$ & $0,00 \mathrm{~B} \mathrm{a}$ & $0,03 \mathrm{~B} \mathrm{a}$ & $0,00 \mathrm{~B} \mathrm{a}$ & $16,36 \mathrm{~A} \mathrm{a}$ & $14,86 \mathrm{~A} \mathrm{ab}$ \\
Pré-embebição $/ 24 \mathrm{~h}$ & $0,03 \mathrm{~B} \mathrm{a}$ & $0,03 \mathrm{~B} \mathrm{a}$ & $0,03 \mathrm{~B} \mathrm{a}$ & $15,85 \mathrm{~A} \mathrm{a}$ & $15,40 \mathrm{~A} \mathrm{a}$ \\
Termoterapia $40^{\circ} \mathrm{C} / 3$ minutos & $0,00 \mathrm{~B} \mathrm{a}$ & $0,00 \mathrm{~B} \mathrm{a}$ & $0,04 \mathrm{~B} \mathrm{a}$ & $12,15 \mathrm{~A} \mathrm{bc}$ & $12,88 \mathrm{~A} \mathrm{abc}$ \\
Termoterapia $50^{\circ} \mathrm{C} / 3$ minutos & $0,00 \mathrm{~B} \mathrm{a}$ & $0,00 \mathrm{~B} \mathrm{a}$ & $0,00 \mathrm{~B} \mathrm{a}$ & $10,25 \mathrm{~A} \mathrm{bc}$ & $11,25 \mathrm{~A} \mathrm{abc}$ \\
Termoterapia $60^{\circ} \mathrm{C} / 3$ minutos & $0,00 \mathrm{~B} \mathrm{a}$ & $0,00 \mathrm{~B} \mathrm{a}$ & $0,04 \mathrm{~B} \mathrm{a}$ & $12,34 \mathrm{~A} \mathrm{bc}$ & $13,60 \mathrm{~A} \mathrm{abc}$ \\
Termoterapia $70^{\circ} \mathrm{C} / 3$ minutos & $0,00 \mathrm{C} \mathrm{a}$ & $0,00 \mathrm{C} \mathrm{a}$ & $0,00 \mathrm{C} \mathrm{a}$ & $14,53 \mathrm{~A}$ ab & $11,45 \mathrm{~B} \mathrm{abc}$ \\
Termoterapia $97^{\circ} \mathrm{C}$ até esfriar & $0,13 \mathrm{~A} \mathrm{a}$ & $0,18 \mathrm{~A} \mathrm{a}$ & $0,04 \mathrm{~A} \mathrm{a}$ & $0,00 \mathrm{~A} \mathrm{bd}$ & $0,65 \mathrm{~A} \mathrm{abd}$ \\
\hline
\end{tabular}

${ }^{1}$ Médias seguidas de mesma letra maiúscula na linha e minúscula na coluna não diferem entre si pelo teste de Tukey a $5 \%$ de probabilidade.

${ }^{2}$ Verde (15-16 DAA), semi-duro (17-19 DAA), duro (20-22 DAA), seco (23-26 DAA) e deiscente (27 DAA), sendo $\mathrm{DAA}=$ Dias após a antese.

Para o vigor das sementes em estudo, observase que os maiores valores do IVG coincidem com as maiores porcentagens de germinação observadas na primeira contagem do teste de germinação e na porcentagem de germinação total, o que corrobora com as informações obtidas por Castro (2005), onde o IVG também coincidiu com a primeira contagem do teste de germinação.

Nas sementes obtidas de frutos secos foi verificado maior IVG nos tratamentos de préembebição estudados, os quais não diferiram da termoterapia a $70^{\circ} \mathrm{C}$ por 3 minutos. Esses resultados evidenciam que neste estádio de maturação a préembebição torna-se um fator importante para aumentar a velocidade de germinação das sementes de quiabo. Sementes menos vigorosas neste estádio de maturação foram verificadas quando se utilizou o tratamento termoterapia a $50^{\circ} \mathrm{C}$ por 3 minutos que foi significativamente igual a testemunha e as termoterapias a 40 e $60^{\circ} \mathrm{C}$ por 3 minutos, com exceção a termoterapia a $97^{\circ} \mathrm{C}$ até esfriar onde houve perda total do vigor. De acordo com Lopes et al. (1998), este tratamento pré-germinativo determinou efeito letal nas sementes de espécies florestais de
Caesalpinea ferrea Mart. ex Tul. Var. leiostachya Benth., Cassia grandis L. E Samanea saman Merrill, após tratamento para superar a dormência. A utilização de água quente afeta acentuadamente o tegumento das sementes, desnaturando as proteínas que o compõe, além de remover substâncias cerosas e aumentar a velocidade de entrada da água pelo calor devido a agitação maior das moléculas, melhorando o processo germinativo (MAYER; POLJAKOFF-MAYBER, 1989). Entretanto, a elevação da temperatura da água de $70^{\circ} \mathrm{C}$ para a temperatura de ebulição (cerca de $97^{\circ} \mathrm{C}$ ) culminou com aumento da porcentagem de sementes mortas de Bauhinia variegata L. (LOPES; BARBOSA; CAPUCHO, 2007).

Em sementes oriundas de frutos deiscentes, a maioria dos tratamentos pré-germinativos foi eficiente para manifestação do vigor das sementes, com exceção dos tratamentos termoterapia a 50 e $70^{\circ} \mathrm{C}$ por 3 minutos e termoterapia a $97^{\circ} \mathrm{C}$ até esfriar (Tabela 3). Assim, o tratamento de termoterapia a $70^{\circ} \mathrm{C}$ por 3 minutos que melhorou o desempenho das sementes de frutos secos de quiabo não demonstrou o mesmo feito nas sementes 
de frutos deiscentes, podendo essa temperatura ser considerada alta para a escarificação das sementes oriundas de frutos deiscentes, devido a diversos fatores, tais como: composição da semente, menor impermeabilidade do tegumento (BEWLEY; BLACK, 1994), duração do período de embebição, grau de umidade e número de sementes testadas (VIEIRA; KRZYZANOWSKI, 1999). Além disso, o tempo de exposição das sementes à água quente pode ter sido decisivo nesse resultado, pois este tempo pode ter sido insuficiente para promover a superação da dormência ou suficiente para provocar a morte das sementes, como registrado para diversas espécies como Desmodium incomum e Lathyrus nervosus (FRANKE; BASEGGIO, 1998), Bauhinia divaricata L. (ALVES et al., 2004), Peltophorum dubium (Spreng.) Taub. (PIROLI et al., 2005) e $A$. esculentus (LOPES et al., 2006a).

Segundo Dias et al. (1999), em sementes de quiabo são necessários até 30 dias para que a germinação se complete, período esse considerado demasiadamente longo, justificando a utilização de técnicas que aceleram a germinação, embora nas Regras para Análise de Sementes (2009) sejam prescritos 21 dias para contagem final da germinação das sementes de quiabo. Os resultados obtidos para os cinco estádios de maturação mostraram que as sementes que não receberam tratamento, de modo geral, diferiram significativamente daquelas oriundas de frutos deiscentes que foram submetidas aos tratamentos de pré-embebição por 6 horas e termoterapia a $50^{\circ} \mathrm{C}$ durante 3 minutos. Em seus estudos, Passam e Polyzou (1997) observaram que frutos de quiabeiro, cultivar Boyiatiou, colhidos imaturos precisam de um período de 60 dias a $25^{\circ} \mathrm{C}$ antes da extração das sementes para que estas obtenham 90\% de germinação. O repouso pós-colheita dos frutos de quiabeiro melhorou a qualidade fisiológica das sementes, principalmente das mais novas, aos 34 e 41 dias após a antese (CASTRO; GODOY; CARDOSO, 2008).

Em síntese, verifica-se que o uso de tratamentos pré-germinativos em sementes de quiabo oriundas de diferentes estádios de maturação dos frutos foi eficiente para acelerar e aumentar a germinação em condições de laboratório, o que corrobora os resultados obtidos por Lopes et al. (2006a), com sementes de quiabo em início de deiscência das vagens submetidas a termoterapia com temperatura de $40,50,60$ e $70^{\circ} \mathrm{C}$ durante 3 minutos.

\section{Conclusões}

As sementes de quiabo oriundas de frutos secos e deiscentes apresentam maior desempenho germinativo.

Os tratamentos pré-germinativos mais eficientes para acelerar a germinação das sementes obtidas de frutos secos e deiscentes são a pré-embebição por 6 horas e a termoterapia a $60^{\circ} \mathrm{C}$ por 3 minutos, respectivamente.

\section{Agradecimentos}

Os autores agradecem ao Programa de Reestruturação e Expansão das Universidades Federais (REUNI) de Assistência ao Ensino vinculado a Coordenação de Aperfeiçoamento de Pessoal de Nível Superior (CAPES) e a Fundação Carlos Chagas Filho de Amparo à Pesquisa do Estado do Rio de Janeiro pela concessão de Bolsas de Doutorado ao primeiro e terceiro autor, respectivamente.

Ao Centro de Ciências Agrárias da Universidade Federal do Espírito Santo (CCA/UFES) e ao Programa de Pós-Graduação em Produção Vegetal do CCA/UFES pelo apoio técnico e científico.

\section{Referências}

ALVES, A. U.; DORNELAS, C. S. M.; BRUNO, R. L. A.; ANDRADE, L. A.; ALVES, E. U. Superação de dormência em sementes de Bauhinia divaricata L. Acta Botanica Brasílica, São Paulo, v. 18, n. 4, p. 871-879, 2004.

BERTAGNOLLI, C. M.; MENEZES, L. N.; STORCK, 
L.; SANTOS, O. S.; PASQUALI, L. L. Desempenho de sementes nuas e peletizadas de alface (Lactuca sativa L.) submetidas a estresses hídrico e térmico. Revista Brasileira de Sementes, Brasília, v. 25, n. 1, p. 7-13, 2003.

BEWLEY, J. D.; BLACK, M. Seeds: physiology of development and germination. 2. ed. New York: Plenum Press, 1994. 445 p.

BRASIL. Ministério da Agricultura e Reforma Agrária. Regras para análise de sementes. Brasília: SNDA/ DNDV/CLAV, 2009. 398 p.

CARVALHO, N. M.; NAKAGAWA, J. Sementes: ciência, tecnologia e produção. 4. ed. Jaboticabal: FUNEP, 2000. $588 \mathrm{p}$.

CASTRO, M. M. Qualidade fiológica de sementes de quiabeiro em função da idade e do repouso pós-colheita dos frutos. 2005. Tese (Doutorado em Agronomia) - Programa de Pós-Graduação em Agronomia. Universidade Estadual Paulista, São Paulo.

CASTRO, M. M.; GODOY, A. R.; CARDOSO, A. I. I. Qualidade de sementes de quiabeiro em função da idade e do repouso pós-colheita dos frutos. Ciência e Agrotecnologia, Lavras, v. 32, n. 5, p. 1491-1495, set./ out. 2008.

CASTRO, R. D.; HILHORST, H. W. M. Embebição e reativação do metabolismo. In: FERREIRA, A. G.; BORGHETTI, F. (Ed.). Germinação: do básico ao aplicado. Porto Alegre, Artmed, p. 149-162, 2004.

COELHO, R. C.; ESTEVES, M. C.; DRUCK, S.; LIBERAL, O. H. T.; DORTA, A. M. C. Efeito da termoterapia sobre a germinação da semente de quiabeiro (Abelmoschus esculentus (L.) Moench). In: CONGRESSO BRASILEIRO DE SEMENTES, 3., 1983, Campinas. Anais... Brasília: ABRATES, 1983.

COUTINHO, W. M.; MANN, R. S.; VIEIRA, M. das G. G. C.; MACHADO, C. F.; MACHADO, J. C. Qualidade sanitária e fisiológica de sementes de milho submetidas a termoterapia e condicionamento fisiológico. Fitopatologia Brasileira, v. 32, n. 6, nov./dez. 2007.

DIAS, D. C. F. S.; PAIXÃO, G. P. da; SEDIYAMA, M. A. N.; CECON, P. R. Pré-condicionamento de sementes de quiabo: efeitos na qualidade fisiológica e no potencial de armazenamento. Revista Brasileira de Sementes, Brasília, v. 21, n. 2, p. 224-231, 1999.

EICHELBERGER, L.; MORAES, D. M. de. Preparo de sementes de quiabo (Abelmoschus esculentus (L.) Moench) para o teste tetrazólio. Revista Brasileira de Sementes, Brasília, v. 23, n. 1, p. 154-158, 2001.

FERNANDES, M. C. A.; CUNHA, R. Efeito da termoterapia sobre o controle de patógenos em sementes de quiabeiro (Abelmoschus esculentus). Fitopatologia Brasileira, Brasília, v. 15, p. 305-307, 1990.

FILGUEIRA, F. A. R. $A B C$ da olericultura: guia da pequena horta. São Paulo: Agronômica, Ceres, 1987. 164 p.

Novo manual de olericultura: agroecologia moderna na produção e comercialização de hortaliças. 3. ed. rev. e ampl. Viçosa: UFV, 2008.

FOWLER, J. A. P.; MARTINS, E. G. Manejo de sementes de espécies florestais. Colombo: EMBRAPA Florestas, 2001. (Documentos, 58).

FRANKE, L. B.; BASEGGIO, J. Superação da dormência de sementes de Desmodium incanum DC. e Lathyrus nervosus Lam. Revista Brasileira de Sementes, Brasília: ABRATES, v. 20, n. 2, p. 420-424, 1998.

KRZYZANOWSKI, F. C.; VIEIRA, R. D.; FRANÇA NETTO, J. B. (Ed.). Vigor de sementes: conceitos e testes. Londrina: ABRATES, 1999. 218 p.

LIMA, D.; GARCIA, L. C. Avaliação de métodos para o teste de germinação em sementes de Acacia mangium Willd. Revista Brasileira de Sementes, Brasília, v. 18, n. 2, p. 180-185, 1996.

LOPES, J. C.; BARBOSA, L. G.; CAPUCHO, M. T. Germinação de sementes de Bauhinia spp. Floresta, Curitiba, v. 37, n. 2, p. 265-274, 2007.

LOPES, J. C.; CAPUCHO, M. T.; KROHLING, B.; ZANOTTI, P. Germinação de sementes de espécies florestais de Caesalpinea ferrea Mart. ex Tul. Var. leiostachya Benth., Cassia grandis L. E Samanea saman Merrill, após tratamento para superar a dormência. Revista Brasileira de Sementes, Brasília, v. 20, n. 1, p. 80-86, 1998

LOPES, J. C.; SILVA, C. A.; SOARES, A. S.; CORRÊA, N. B. Germinação e vigor de sementes de quiabo em início de deiscência das vagens e tratadas com termoterapia. In: CONGRESSO BRASILEIRO DE OLERICULTURA, 46., 2006, Goiânia. Anais.... Goiânia: Associação Brasileira de Horticultura, v. 24, p. 2417-2420, 2006 a.

LOPES, J. C.; SILVA, C. A.; SOBREIRA, F. M.; MACEDO, C. M. P. de; MATHEUS, M. T. Influência dos estádios de maturação na germinação e vigor de sementes de quiabo. In: CONGRESSO BRASILEIRO DE OLERICULTURA, 46., 2006, Goiânia. Anais.... Goiânia. Associação Brasileira de Horticultura, v. 24, p. 2549-2552, 2006b.

LOPES, M. de M. Testes de vigor em sementes de quiabeiro. 2007. Tese (Doutorado em Agronomia) - Programa de Pós-Graduação em Agronomia. 
Universidade Estadual Paulista, São Paulo.

MAGUIRE, J. B. Speed of germination-aid in selection and evaluation for seedling emergence vigor. Crop Science, Madison, v. 2, n. 2, p. 176-177, 1962.

MARCOS FILHO, J. Fisiologia de sementes de plantas cultivadas. Piracicaba: Fealq, 2005. 495 p.

MATHEUS, M. T.; LOPES, J. C. Termoterapia em Sementes de Guapuruvú (Schyzolobium parahyba (Vell.) Blake). Revista Brasileira de Biociências, Porto Alegre, v. 5, p. 330-332, jul. 2007. Suplemento 2.

MAYER, A. C.; POLJAKOFF-MAYBER, A. The germination of seeds. London: Pergamon Press, 1989. 270 p.

MENTEN, J. O. M. Patógenos em sementes, detecção, danos e controle químico. São Paulo: Ciba Agro, 1995.

NAKAGAWA, J.; CAVARIANI, C.; ZUCARELI, C. Maturação, formas de secagem e qualidade fisiológica de sementes de mucuna-preta. Revista Brasileira de Sementes, Pelotas, v. 27, n. 1, p. 45-53, 2005.

PASSAM, H. C.; POLYZOU, P. Improvement of okra seed germination by acid, osmoconditioning and hot water treatments. Plant Varieties and Seeds, Athens, v. 10, n. 2, p. 135-140, 1997.

PIROLI, E. L.; CUSTÓDIO, C. C.; ROCHA, M. R. V.; UDENAL, J. L. Germinação de sementes de canafístula Peltophorum dubium (Spreng.) Taub. tratadas para superação da dormência. Colloquium Agrariae, Presidente Prudente, v. 1, n. 1, p. 13-18, 2005.

SILVA, A. M. S.; CARMO, M. G. F.; OLIVARES, F. L.; PEREIRA, A. J. Termoterapia via calor seco no tratamento de sementes de tomate: eficiência na erradicação de Xanthomonas campestris pv. Vesicatoria e efeitos sobre a semente. Fitopatologia Brasileira, Brasília, v. 27, n. 6, p. 586-593, nov./dez. 2002.

SONNENBERG, P. Olericultura especial. $2^{\text {a }}$ parte. 3 . ed. Goiânia: UFG, 1985. 149 p. (Informações Técnicas).

SOUZA, E. A. C.; MARTINS, C. C.; SADER, R. Quebra de dormência de sementes de quiabo (Abelmoschus esculentus (L.) Moench) cv. Santa Cruz. Ciência Agronômica, Jaboticabal, v. 7, n. 1/2, p. 19-23, 1992.

SOUZA, J. R. P. de; TAKAHASHI, L. S. A.; YOSHIDA, A. E.; GUIRAUD, M. C.; ROCHA, J. N. Tempo de armazenamento e temperatura na porcentagem e velocidade de germinação das sementes de camomila. Ciência Rural, Santa Maria, v. 37, n. 4, p. 982-986, jul./ ago. 2007.

UNIVERSIDADE FEDERAL DE VIÇOSA - UFV. Sistema para análises estatísticas e genéticas - SAEG.
Versão 9.1. Viçosa: Universidade Federal de Viçosa, 2007. (Versão 8.0).

VAZQUEZ-YANES, C. The use of a thermogradient bar in the study of seed germination in Ochroma lagopus. SW. Turrialba, San Jose, v. 25, n. 3, p. 328-330, 1975.

VIEIRA, R. D.; KRZYZANOWSKI, F. C. Teste de condutividade elétrica. In: KRZYZANOWSKI, F. C.; VIEIRA, R. D.; FRANÇA NETO, J. B. (Ed.). Vigor de sementes. conceitos e testes. Londrina: ABRATES, cap. 4, p. 1-26, 1999.

ZAMBOLIM, L.; VALE, F. X. R.; COSTA, H. Controle integrado de doenças de hortaliças. Viçosa: Suprema Gráfica e Editora Ltda, 1997.

ZANIN, A. C. W.; NAKAGAWA, J.; SETUBAL, J. W. Efeitos da idade dos frutos, método e condição de secagem sobre a qualidade de sementes de quiabeiro. Pesquisa Agropecuária Brasileira, Brasília, v. 33, n. 7, p. 1-5, jul. 1998 . 
Martins, C. A. S.; Lopes, J. C.; Macêdo, C. M. P. 